\title{
LAS HABLAS DE NEGROS. ORÍGENES DE UN PERSONAJE LITERARIO
}

\author{
Consolación Baranda Leturio \\ Universidad Complutense
}

Es cosa sabida que, en un buen número de obras teatrales del siglo XVI, la comicidad se basa en la presencia de determinados personajes cuyo carácter cómico residía en su especial manera de hablar: el pastor rústico, el morisco, el negro o el vizcaíno. A este respecto, basta recordar la alabanza que dirige Cervantes a Lope de Rueda, por la "propiedad" con la que hacía los papeles "ya de negra, ya de rufián, y ya de bobo y ya de vizcaíno" 1 . Los negros aparecen en la literatura romance, como personajes literarios, en el Cancioneiro Geral de Resende, ya con la intención de provocar la risa en los receptores ${ }^{2}$.

Esta relación entre el negro y la comicidad es nueva y, en mi opinión, está estrechamente relacionada con factores políticos y sociales de la época; es decir, para la creación de estos personajes se parte de la realidad y se prescinde de la tradición literaria previa. De hecho, hay un enorme contraste entre el tratamiento y la consideración del negro como personaje literario en el siglo xvi y los de la literatura clásica.

A este respecto, es fundamental la diferencia de origen geográfico; el de los negros del mundo clásico es siempre Etiopía. Los etíopes aparecen en la Iliada como un pueblo especialmente amado por los dioses, a causa de su piedad y de su sentido de la justicia, razón por la que gozaban de gran

1 Miguel de Cervantes, Entremeses, ed. Eugenio Asensio, Madrid, Castalia, 1970, pág. 11.

2 Cancioneiro Geral de García de Resende, ed., int. y notas Alvaro J. de Costa Pimpõo e Aida Fernanda Dias. Coimbra, Centro de Estudios Românicos (Instituto de Alta Cultura), 1973. Uno de ellos es de Fernã da Silveira (vol. I, comp. 44, pág. 82), se escribió hacia 1455; el otro, de Anrrique da Mota (vol. II, comp. 797, págs. 253-255), hacia 1510. 
respeto en el mundo greco-latino. Son negros Euridates, el más íntino compañero de Odiseo, y el rey Mennon, que participó en la guerra de Troya.

En una época tardía, sólo Plutarco en sus Vidas (Brutus, 48) insinúa una opinión peyorativa, al asociarlos con la mala suerte ${ }^{3}$.

En el teatro romano de Plauto y Terencio hay dos esclavas negras. En el Poenulus de Plauto, Giddenis es una fiel criada que cuida a dos jóvenes, secuestradas y vendidas como esclavas. Se la describe como una negra de aspecto agradable (I.114), que, además de destacar por su fidelidad, habla cartaginés y correcto latín. En el Eunuchus de Terencio, Fedria compra una esclava etíope; después, su rival, Trasón, alude a su escaso valor.

Se trata de personajes sin intención cómica, lo que es especialmente significativo en el caso de Plauto que tantos criados graciosos introdujo en sus comedias.

Posteriormente, hacia el siglo Iv d. de C., las Etiópicas de Heliodoro son un exponente claro de la idealización de Etiopía y de las costumbres de sus habitantes. Etiopía es el país en el que "el oro se emplea para todos los usos que el hierro cumple entre los demás pueblos" ", y tanto sus sacerdotes - gimnosofistas - como su rey son verdaderos dechados de virtudes, modelos de rectitud, justicia y piedad.

La influencia de esta obra en la literatura española fue grande, pero bastante tardía. Las primeras versiones no griegas aparecen después de 1547 , año en que se publicó la edición francesa; hasta 1554 no se editará la primera versión castellana, fecha muy posterior a la aparición del negro literario. Mientras en la literatura greco-latina siempre se designa a los negros como etíopes, en la literatura española, hasta la mitad del siglo XVI, apenas se encuentra alguno de esta procedencia ${ }^{\sqrt{5}}$; sus lugares de origen están en la zona occidental de África y coinciden con los de los esclavos importados a través de Portugal, a partir de la paz de Alcovaças en $1476^{\circ}$.

3 F. H. Snowden Jr., Blacks in Antiquity. Ethiopians in the Greco-Roman Expericnce. Cambridge, Massachussets, The Belknap Press of Harvard Univ. Press., 1970, passim.

4 Heliodoro, Las Etiópicas o Tcágcnes y Cariclea, introd., trad. y notas de Emilio Crespo Güemes, Madrid, Gredos, 1979, págs. 386 y sigs.; véanse también pág. 33 de la introducción, pág. 155 y episodios finales.

- "Explica el libro que este rey Escariano era de muy gran cuerpo y bella disposición, muy fuerte y valentísimo caballero, y completamente negro, pues era señor de los negrines de Etiopía, y era llamado el rey Jamjam". Joanot Martorell, Marti Joan del Galba: Tirant lo Blanc, Madrid, Alianza, 1969, t. II, pág. 343.

- Sobre la esclavitud en España: A. Domínguez Ortiz, "La esclavitud en Castilla durante la Edad Moderna", Estudios de Historia Social de España, II, 1952, págs. 369428; Ruth Pike, Aristócratas y comerciantes, Barcelona, Ed. Ariel, 1978, págs. 181-200; Verlinden, Ch., "L’Esclavage dans la Péninsule Ibérique au xive siècle”, Anuario de 
Es significativo que la aparición del negro como tipo literario se produzca cuando la importación de esclavos de las factorías africanas empezó a ser un negocio de gran envergadura; estos negros no podían ser asimilados a la tradición clásica, de ahí la ruptura en el tratamiento literario.

A partir de este momento los negros serán la única etnia dedicada de forma exclusiva a la esclavitud ${ }^{7}$; en consecuencia, sus países y costumbres se considerarán bárbaros e inferiores, rasgo al que aluden la mayor parte de los textos literarios en los que aparecen.

Ya en el poema de Fernã da Silveira del Cancioneiro Geral de Resende, el rey de Sierra Leona se ofrece a bailar con motivo de las fiestas por la boda de Doña Juana con Enrique IV de Castilla: "balhar que saber como nossa terra”. Se parodia su forma de hablar portugués y desempeña una función bufonesca, pese a que es también un rey.

También encontramos reyes negros en la Comedia Trofea de Torres Naharro, escrita con ocasión de la ostentosa embajada del rey Don Manuel de Portugal al Papa León X, en 1514. En la jornada primera, la Fama senala las tierras ganadas por el rey de Portugal, entre otras: “... / y más saber te conviene: / que a Guinea / este rey la señorea, / y a Mandinga, que propongo, / y a Gelof y al Monicongo, / ..." 8 .

Los reyes de estos países se presentan ante el Papa como vasallos del de Portugal e, introducidos por un intérprete, piden recibir el bautismo, como hicieron los romanos a los "barones de Atenas".

Esta cita, además de corroborar la conciencia de superioridad sobre estos pueblos, permite comprobar que es, precisamente, de estos países de donde proceden los negros que encontraremos en los textos de la primera mitad del XVI. Es decir, se asocia a estos personajes con la realidad histórica coetánea, no con los etíopes del mundo clásico.

En la segunda composición del Cancioneiro Geral de Resende ${ }^{\circ}$, un clérigo acusa a una negra, esclava suya, de haber derramado "una pipa" de vino y la llama "perra de Maniconguo".

También en la literatura española anterior a Lope de Rueda —período

Estudios Medievales, 7, 1971, y J. Heers, Esclaves et domestiques au Moyen Age dans le monde méditerranéen, Paris, Fayard, 1981.

7 También había esclavos moriscos, más cotizados que los negros debido a su habilidad en determinados oficios, y a que tras la Reconquista escaseaban más. Véase, por ejemplo, Graullera, V., La esclavitud en Valencia durante los siglos XVI y XVII, Valencia, CSIC, 1978; Franco Silva, A., La esclavitud en Andalucía al término de la Edad Media, Madrid, D. L., 1984.

8 Gillet, Propalladia and other works of B. Torres Naharro, Pennsylvania, Philadelphia University Press, 1961, vol. II, pág. 95.

- Op. cit., vol. II, págs. 253-255. 
al que se limita este trabajo- se encuentran abundantes alusiones a la procedencia de los personajes negros.

Los primeros textos de la literatura española en los que aparecen negros son dos coplas de Rodrigo de Reinosa; se desconoce la fecha de composición, pues se conservan en un pliego suelto sin fecha, lugar, ni nombre del impresor ${ }^{10}$. Hay otra copla atribuida a Reinosa, aunque no lleva su nombre como las anteriores, ya impresa en 1524, en la que una señora requiere de amores a un esclavo negro, mientras su marido está en Tierra Santa. El esclavo accede a los deseos de la señora a cambio de que le quite las argollas ${ }^{11}$.

No hay nada en estas coplas que pueda relacionarlas con las de Rodrigo de Reinosa, ni en la forma ni en el contenido ${ }^{12}$. Este poema y la posterior Comedia Pródiga de Luis de Miranda son dos casos aislados, a causa de su tratamiento no cómico del negro.

Aparecen también negros en algunas Farsas de Diego Sánchez de Badajoz (Farsa de Moysem, Farsa de la fortuna, Farsa Theologal, Farsa de la ventera y Farsa de la hechicera), en la Lozana andaluza de Francisco Delicado, en la Farsa o tragedia de la castidad de Lucrecia de Juan Pastor, en la Comedia Tesorina de Jaime de Güete y en la Segunda y Tercera parte de La Celestina.

En la Farsa Theologal, un pastor insulta a una negra y dice: "suéltame negra mandinga / ... / suelta ya puta guinea /" (versos 1.443 y sigs.); en

10 Antonio Rodríguez Moñino, Diccionario de pliegos sueltos poéticos (S. XVI), Madrid, Castalia, 1970, pág. 317, núm. 469.

11 La copla se titula "Canta, Jorgico, canta". En Cancionero de obras de burlas y provocantes a risa. Ed. de J. A. Bellón y P. Jauralde Pou. Basado en la ed. original (Valencia, 1519) con las composiciones suprimidas del Cancionero Geral de Hernando del Castillo y las adiciones y "Advertencias" de Luis de Usoz y Río, Madrid, Akal, 1974. Usoz en su "Advertencia” (ed. cit., pág. 19) dice “... el diálogo de Jorgico, esclavo morisco sin duda ...", afirmación con la que no estoy de acuerdo; sí comparto la opinión de Russell. No hay más que una alusión a la raza en el texto: “... que aunque de color mohíno, la plática tienes blanca", color que conviene tanto a los moriscos como a los negros. De hecho, se dirige a un negro este adjetivo en la Farsa de Moysem, de Sánchez de Badajoz; y por otro lado, el habla de Jorgico, aunque correcta, en el estribillo "no quere cantá" tiene más relación con la de los negros que con los hábitos lingüísticos de los moriscos. También en Antonio Rodríguez Moñino, op. cit., pág. 460, núm. 786, Coplas de como una dama.

12 “El estilo no recuerda particularmente el de la obra de Reinosa en general. (...) parece improbable que Cromberger, si hubiera creído que el poema era obra de Reinosa, hubiera dejado de llamar la atención sobre el hecho..." P. E. Russell, Temas de la Celestina, Barcelona, Ariel, 1978, págs. 379-406. Publicado con el título "Towards an interpretation of Rodrigo de Reinosa's «poesía negra»", en Studies in Spanish Litterature of the Golden Age. Presented to Edward M. Wilson, Londres, ed. R. O. Jones, 1973, págs. 225-245. 
la Farsa de Moysem, otro pastor repite: "suéltame negro mandinga" ${ }^{13}$. En la Lozana andaluza no se alude a la procedencia de la negra, pero Lozana le pregunta si su nombre es "Comba" 14. Este es el nombre de la negra en la primera de las composiciones de Reinosa ; según Rusell ${ }^{15}$, sólo se encuentra en contextos gelofes y mandingas y proviene de Kumba, nombre todavía frecuente en Senegal.

La negra Margarita de la Comedia Tesorina ${ }^{16}$ emplea el vocablo "mandinga", en un contexto que no he podido entender: “... xu xartero di mandinga".

Estas alusiones indican que se relacionaba a estos personajes con su situación histórica y social coetánea. El desprecio hacia sus culturas y su especialización como esclavos determinará el carácter cómico de estos personajes en la literatura.

Precisamente, hasta Lope de Vega no se inicia la dignificación literaria del tipo, que comenzará con El santo negro Rosambuco de la ciudad de Palermo y El negro de mejor amo ${ }^{17}$. Ahora bien, esta "dignificación" se produce cuanclo los personajes proceden de Etiopía; no se trataría de la evolución de un tipo literario, sino de la confluencia, en algunas obras, de dos tradiciones diferentes: la de la literatura del siglo XVI, con sus negros cómicos, y la de la literatura greco-latina, con sus dignos etíopes ${ }^{\mathbf{1 8}}$.

\section{EL HABLA}

La presencia de los negros en casi todos los textos de la primera mitad del siglo xvi tiene una finalidad cómica. Además, son siempre personajes secundarios, esclavos o criados de ínfima categoría, y sólo en la Farsa Theologal tiene la negra un papel importante en la estructura de la obra. En todos los casos, el mecanismo de la comicidad se basa en el mismo rasgo: su pe-

18 Diego Sánchez de Badajoz, Recopilación en metro (ed. fac.), Madrid, RAE, 1929 , folio cii v.

14 Francisco Delicado, La Lozana andaluza, ed. C. Allaigre, Madrid, Cátedra, 1985, pág. 284.

15 P. E. Russell, op. cit., pág. 397.

16 Jaime de Güete, "Comedia intitulada Tesorina", en Teatro español del siglo XVI, Madrid, ed. Biblióf. Madr., 1913, tomo I, págs. 81-170.

17 F. Weber de Kurlat, "El tipo del negro en el teatro de Lope de Vega: Tradición y creación", NRFH, XIX, págs. 337-359.

18 Posiblemente, el tema del elogio de la belleza de las negras y mulatas habria que estudiarlo no tanto a la luz de la dignificación de estas figuras, como hace $F$. Weber, sino diferenciado del tema del negro, como un tópico propio del barroco y en relación con otros escritores: véase Quevedo, por ejemplo, en La hora de todos, XXXVII. 
culiar manera de hablar castellano. Como explica Covarrubias, bastantes años después, a propósito del refrán callar como negra en baño, "en el baño entran todos sin luz y assí no se puede distinguir quáles son negros o blancos, si ellos no se descubren hablando" ${ }^{10}$.

Pero para que haya un efecto cómico es necesaria la exageración de las peculiaridades lingüísticas y la familiaridad de los receptores con las mismas. Por ello, lo que importará al escritor será agudizar las distorsiones y diferencias con lo que se consideraba la norma lingüística, y no la exactitud en la reproducción de la jerga, aunque se base en ella. Esto sucede, por otra parte, en muchos textos anteriores y coetáneos a la aparición de los negros como personajes literarios. En ellos no es rara una forma "primitiva" de comicidad, basada en la caricatura de determinados personajes, de baja extracción social siempre, a los que se ridiculiza por el mismo procedimiento: la exageración de determinados rasgos lingüísticos.

En el caso del habla de negros, los demás personajes entienden perfectamente su jerga, e incluso la remedan para dirigirse a ellos. La comicidad, a excepción de la Farsa Theologal y la Comedia Tesorina, reside en el mero trasunto lingüístico, no en las confusiones que pudiera originar el deficiente dominio de la lengua; ésta es la razón por la que hablaba antes de una forma poco elaborada o primitiva de comicidad. Será Lope de Rueda el que dote a sus negros de unos rasgos psicológicos más sistematizados y el que explote con éxito el recurso de las confusiones.

Pero, ¿cómo es el habla de negros en la literatura española? Algunos estudios se centran en los aspectos fonéticos, como sucede con los de E. de Chasca y $\mathrm{F}$. Weber de Kurlat ${ }^{20}$. El primero intenta establecer la procedencia africana de los distintos rasgos fonéticos, y el segundo atiende exclusivamente a la descripción pormenorizada de estos rasgos. Son importantes, asimismo, los trabajos de P. Teyssier, a propósito de Gil Vicente, y de A. Naro ${ }^{21}$.

Acerca de las dificultades que plantea la sistematización del "guineo", son muy significativas las palabras de F. Weber:

En resumen, las hablas de negro en el teatro del siglo xvi presentan elementos comunes a varias de ellas y elementos peculiares de cada autor, pero aun

10 Cita ya este refrán Alonso Martínez de Toledo, en Arcipreste de Talavera o Corbaaho, ed. J. González Muela, Madrid, Castalia, 1970, pág. 82.

20 Edmund de Chasca, "The phonology of the speech of the negroes in early Spanish drama", $H R$, XIV, 1946, págs. 323-339. F. Weber de Kurlat, "El tipo cómico del negro en el teatro prelopesco. Fonética", Filología, VIII, 1962, págs. 139-168.

21 Paul Teyssier, La langue de Gil Vicente, Paris, Klincksieck, 1959. Anthony J. Naro, "A study on the origins of pidginization", Language, 54, núm. 2, 1978, páginas 314-347. 
en aquellos aspectos en los que a primera vista parece haber mayor uniformidad de utilización de motivos, el análisis atento señala diferencias: mayor sistematización, matices de preferencia por una $\mathbf{u}$ otra posibilidad ${ }^{22}$.

En cualquier caso, si la aparición del negro en la literatura coincide con un fenómeno histórico concreto -el incremento de negros esclavos traídos de Africa occidental-, parece razonable pensar que en los primeros textos se mezclarían rasgos tomados de la realidad, con mayor o menor acierto, con otros elementos que, en aras de la comicidad, pretenderían caricaturizar la forma de hablar de los negros. Después, y a medida que los nuevos personajes se fueran haciendo más familiares para los receptores, la relación de estas hablas con la situación real, no literaria, va perdiendo sentido, y la convencionalización del negro como tipo literario se acompaña de una forma de hablar más convencionalizada a su vez.

A este propósito, señala Germán de Granda que: "la constitución de las hablas de grupo social o geográfico, que aparecen con cierta frecuencia en obras literarias de todos los países, está determinada por la conjunción diferente en cada caso en cuanto a sus proporciones, de dos factores esenciales: la reproducción de la realidad y la estilización creadora ..." ${ }^{28}$, y relaciona este problema con la discusión sobre el origen del sayagués literario.

Quizá así se pueda explicar el proceso que va desde la disparidad en las hablas de negros entre los distintos autores de la primera mitad del siglo XVI, hasta la uniformidad del xvil, cuando Quevedo afirma que: "Si escribieres comedias y eres poeta sabrás guineo en volviendo rr-1l, y al contrario: como Francisco, Flancico; primo, plimo" ${ }^{24}$.

Este proceso tiene su punto de inflexión en la obra de Lope de Rueda. Hasta entonces coexisten dos formalizaciones distintas del "guineo"; el rasgo que las diferencia es la presencia o no del "xexeo", es decir, la conversión del sonido $|\mathbf{s}|$ en $|\mathbf{s}|$. Este sonido está ausente del habla de negros en las obras de Sánchez de Badajoz y de Lope de Rueda, que lo utilizan, en cambio, como rasgo caracterizador de la jerga morisca. En las coplas de R. de Reinosa solamente hay dos casos - moxca y moxquito-, pero aparece en boca de negros en La lozana andaluza, la Farsa de Lucrecia, la Comedia Tesorina, la Segunda Celestina y la Tercera Celestina ${ }^{20}$.

22 F. Weber de Kurlat, "El tipo cómico ...", pág. 167.

28 Germán de Granda, Estudios lingüisticos hispánicos, afrohispánicos y criollos, Madrid, Ed. Gredos, 1978, pág. 216.

24 Citado por Manuel Alvarez Nazario, El elemento afronegroide en el español de Puerto Rico, San Juan de Puerto Rico, Instituto de Cultura Puertorriqueña, 1961, pág. 134.

- Juan Pastor, Farsa o tragedia de la castidad de Lucrecia, ed. A. Bonilla y San Martín, "Cinco obras dramáticas anteriores a Lope de Vega", RHi, XXVII, 1912, 
Hay, pues, un mayor número de autores que emplea el "xexeo" como elemento diferenciador del habla de negros, en la primera mitad del xvi. Sin embargo, a partir de Lope de Rueda, este sonido $|\check{s}|$ dejará de aparecer en boca de negros y lo hará exclusivamente en los diálogos de moriscos.

Da la impresión de que esta especialización posterior surge cuando estos tipos cómicos han adquirido una mayor estilización literaria; así, el público podría distinguir inmediatamente, con sólo oír su forma de hablar, si el personaje era guineo, moro, gitano, etc. Pero, ¿por qué aparece el sonido $|\mathbf{s}|$ en boca de bastantes negros en este primer momento de su vida literaria?

Parece demasiada casualidad que cinco autores diferentes utilicen el "xexeo" como una, entre otras, de las características fonéticas del guineo, por pura arbitrariedad; tampoco es plausible que todos ellos confundieran negros con moriscos.

A este respecto, de Chasca se limita a comentar que: “The ' $x$ ' represents the sound of 'sh' in 'shall'. This pronunciation is typically Arabic, not negro" ${ }^{26}$. Albert E. Sloman llega a decir, a propósito de la pareja de negros en la Segunda Celestina: "Zambrán and Boruca are designated negroes, though both speak a jargon which contains all the esential Moorish characteristics and none distinctive of 'guineo"' ${ }^{27}$.

Quizá el superior conocimiento de los hábitos lingüísticos de los moriscos, sobre los cuales se conservan abundantes datos documentales, ha facilitado esta tendencia a concederles la exclusiva de la transformación de $|s|$ en $|\check{s}|$. Esta transformación se produce en los textos escritos y también en la lengua hablada, como prueban los comentarios de Nebrija y Juan de Valdés ${ }^{28}$.

Ahora bien, si los textos literarios son el único testimonio acerca del habla de negros en la época, aunque no se deban confundir con documentos lingüísticos, tiene que haber alguna explicación al hecho de que, en ellos, algunos negros transformen también $|\mathbf{s}|$ en $|\check{s}|$.

De la complejidad del problema del habla de negros dan fe los distintos enfoques metodológicos de los trabajos consultados y, sobre todo, la presencia en ellos de afirmaciones aparentemente irreconciliables. Así, para E. de

págs. 437-454. Feliciano de Silva, Segunda Comedia de Celestina, ed. C. Baranda, Madrid, Cátedra, 1988. Gaspar Gómez, Tercera parte de la Tragicomedia de Celestina, ed. Mac E. Barrick, Philadelphia, Univ. of Pennsylvania Press, 1973.

28 E. de Chasca, “The phonology of the speech ...", pág. 337.

27 Albert E. Sloman, "The phonology of moorish jargon in the works of early spanish dramatists and Lope de Vega", MRL, XLIV, 1949, págs. 207-217, pág. 208.

28 Poema de Yúçuf, ed. Menéndez Pidal, prólogo de M. Alvar, Granada, Univ. de Granada, 1952, pág. 44 (la edición de R. Menéndez Pidal se publicó en Revista de Archivos, Bibliotecas y Museos, VII, 1902). Véase también Amado Alonso, "Trueques de sibilantes en antiguo español", $N R F H, 1,1947$, págs. 1-12. 
Chasca, el "xexeo" es rasgo propio de los moriscos y no de los negros, porque :

In the account which Delafosse gives of the phonology of the sixty languages of the Ivory Coast, and neighboring districts - a region from which many slaves came to Portugal and Spain- he points out that the natives cannot pronounce $s h[s]$ or $z h$ as in azure [3] ${ }^{20}$.

Por el contrario, M. Álvarez Nazario afirma que ese sonido sh se daba en algunos dialectos africanos:

En la lengua mendé de la familia sudanesa mandinga, el cambio $s>s h$ se da en inicio de palabra, y también en posición interior en las hablas bantús, según ilustran indirectamente los ejemplos que siguen (en los que ch o $x$ ortográficas equivalen al sonido portugués parejo al inglés $s h$ ), tomados del negro portugués de Angola, Santo Tomé y Annobón, coincidentes asimismo con usos recogidos en Cabo Verde: chim "sin", chintinella "sentinela" (...). El papia-

1 miento evidencia también el paso $s>s h$ : cushina "cocina" (...). Igualmente, en el pasado, en el lenguaje hispanonegroide del Río de la Plata: shemana "semana", shabrosha "sabrosa", she "se" ... ${ }^{30}$.

Como señalaba antes, parte de los esclavos eran mandingas (v.gr., los de las Coplas de Rodrigo de Reinosa), y precisamente en Cabo Verde hubo una factoría esclavista a principios del xvI. El problema es el siguiente: ¿es posible que algunos esclavos del origen señalado por Alvarez Nazario conservasen ciertos rasgos fonéticos de sus lenguas nativas al intentar hablar después el castellano? En caso de que la respuesta fuese afirmativa, la transformación $|s|$ y $\mid$ š de este grupo de obras reflejaría la forma de hablar de, al menos, algunos esclavos negros.

Cuestión distinta es el abuso del "xexeo" por parte de los negros literarios, que sí pudo deberse a la relación que existía entre ambas etnias -árabes y negros-, pues hay datos que muestran cómo en esta época se consideraban afines; así, el rasgo lingüístico peculiar del morisco, más familiar, pudo hacerse extensivo a los negros, en su primera andadura literaria.

\section{NEgRos y ÁRABES}

Los negros traídos por los portugueses procedían de las factorías de Cabo Blanco hasta comienzos del siglo xvi y de Cabo Verde después; sus lugares

29 E. de Chasca, art. cit., pág. 331.

so M. Alvarez Nazario, op. cit., págs. 144 y 145. 
de origen eran diversos, abarcaban desde el río Senegal hasta la actual $\mathrm{Ni}$ geria e incluso zonas muy interiores del continente.

$\mathrm{Ya}$ en el siglo viI, los árabes habían iniciado el comercio con el antiguo imperio de Ghana; hay testimonios de invasiones almorávides anteriores al siglo XI y de la posterior islamización del país. También los estados de Tekrour, Guinea y Mali fueron parcialmente islamizados, aunque a la vez pervivía el animismo. Hay, además, testimonios portugueses que señalan la existencia de pueblos mandingas islamizados en zonas costeras occidentales en los siglos $\mathrm{xV}$ y xvi. Consiguientemente, buena parte de esclavos negros importados serían musulmanes ${ }^{81}$.

Algunos textos literarios corroboran esta relación entre ambas etnias. A veces se encuentran mezcladas en ellos las designaciones de "negro" y "moro". Así, en el Cancioneiro Geral se alude al baile del rey negro de Sierra Leona como "mourisca ratorta". En la Farsa Theologal el cura se asombra a causa de la negra y dice: “ no estar bautizada! / ¿Entre christianos y mora?" 32 .

La primera intervención del negro de la Segunda Celestina es: "'́antar, vailar Mohoma", alusión indirecta a su religión, y en la Tercera Celestina, Poncia dice a la negra Boruga: "qué dizes, negra ...?”, mientras más adelante se refiere a ella diciendo: "Poncia, tenla a essa mora ..." ss.

Confirmaría esta relación la aparición de algunos arabismos en boca de personajes negros, en estos primeros textos; en concreto, los términos taybo, marfuz (con las formas correspondientes al femenino) ${ }^{\text {s4 }}$ y gualá.

31 V. Monteil, L'Islam noir, Paris, Ed. du Seuil, 1971, págs. 64 y sigs. Véase también Jacques Heers, Esclaves et domestiques au Moyen Age dans le monde méditerranéen, Paris, Fayard, 1981, págs. 88 y sigs., y G. de Granda, "Datos antroponómicos sobre negros esclavos musulmanes en Nueva Granada”, Thesaurus, XXVII, 1972, páginas 89-103.

82 D. Sánchez de Badajoz, Farsas, ed. J. M.a Díez-Borque, Madrid, Cátedra, 1978, pág. 108, vv. 1.030-1.031.

88 Gaspar Gómez, ed. cit., págs. 116 y 117.

s4 El término "marfuz" aparece ya en el Libro de buen Amor, verso 119 d. "Taybo", en cambio, sólo lo hace en estos textos y dicho por negros. Carolina Michaelis de Vasconcelos lo estudia en "Taibo", Revista Lusitana, XII, págs. 133-138 (reproducido en Dispersos, originais portugueses, Lisboa, Edição da Revista Ocidente, 1969, vol. I, páginas 182-186). Comienza este artículo diciendo: "Têm razão os dois eruditos que dão ao adjectivo taibo o significado de bom e derivam do arábico taib [Taib]. Tanto o sentido como a origem, e tambén a aplicação a Mouros (quer pretos, quer brancos, quer baços, isto é, da Guiné, de Tunes ou de Cambaia)." Señala en la nota 3 que aparece en el "Cancioneiro Geral, I, 172, em, 229 (como oposto a marfuz)". Este es el sentido que tiene en todos los textos españoles también. Al final de su artículo hace notar su extrañeza de que "¿Por que motivo não se usaria o feminino taiba?". Precisamente en las Coplas de R. de Reinosa se utiliza la forma femenina calificando al sustantivo "gente". 
El rey de Sierra Leona del Cancioneiro Geral dice: "gente meu taybo". En las Coplas de Rodrigo de Reinosa leemos:

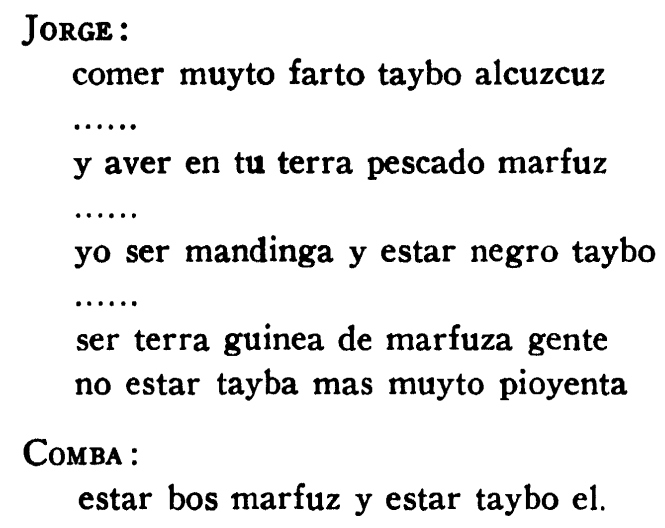

En la Comedia Tesorina, el pastor Giliracho dice a la negra Margarita, remedando su forma de hablar: "¿Qué quebrareyx box marfux ?” Por último, Boruga, la esclava negra de la Tercera Celestina comenta: "Para yo dexemulaxones no extar a mi taibo ..."

En cuanto al término gualá, para A. E. Sloman se trata de un arabismo que, sin embargo, no aparece en boca de ningún árabe entre los textos anteriores a Lope de Vega que él estudia; respecto a su presencia en los diálogos de los negros en la Segunda Celestina comenta:

... there are a number of examples of the form guala, namely the voicing of the $\mathrm{k}$ sound in cual. This too may derive from fact, for though $q$ and $c$ are not confused in aljamiado texts, the Arabic equivalent of the [k] sound, qaf 3 , seems to have approximated Granada and elsewhere to the voiced Spanish sound $[\mathrm{g}]^{\mathrm{B5}}$.

Por su parte, E. de Chasca considera la transformación c $>\mathrm{g}$, en la $\mathrm{Se}$ gunda Celestina, como totalmente caprichosa ${ }^{\circ 8}$.

La negra Boruca dice en esta obra: “... encomendarme a Zambrán que, gualá, estar bon hejo, aunque travexo y veliaco". Zambrán escribirá una carta a su enamorada Boruca en la que le dice: “... xeñora de mi coraçón: gualá, querer a ti como a me vida (...). Dexir a mí no xaber, xabendo que todo lo haxer tú ...". Boruca comenta esta carta en los siguientes términos: "Gualá estar ven excrita, max a me no se me dar nada ..."

No es ésta la primera aparición del término; en las Coplas de Reinosa, Comba contesta a las proposiciones de Jorge, de "fazer choque choque", diciendo: "Gualá nunca herrar le le / andar vos y vete marfuz achur chur ..."

A. Sloman, art. cit., pág. 211.

s E. de Chasca, art. cit., pág. 338. 
En realidad, se trata del arabismo wa llah 'por Alá', exclamación que aparece en el Libro de Buen amor, v. 1.510 d: “... diz la mora: 'Legualá"” 37.

Lo significativo del caso es que este arabismo aparezca, en la primera mitad del siglo xVI, exclusivamente en textos que pretenden reproducir el habla de negros.

Pienso que es una simplificación equivocada identificar "xexeo" con el habla morisca; los cruces que se producen entre el guineo y lo morisco descansan en razones históricas y responden a una realidad concreta, realidad que, en aras de una mayor eficacia teatral, se va diluyendo cada vez más.

A continuación se estudian los rasgos fonéticos y morfosintácticos del habla de negros en los textos en los que el "xexeo" es una de las características de su jerga: La lozana andaluza, Farsa de Lucrecia, Segunda Celestina, Tercera Celestina y Comedia Tesorina. El propósito es delimitar sus relaciones en la reproducción de esta jerga y si, además, difieren de la forma de hablar en otros textos coetáneos.

\section{EL hABLA DE NEGROS: FONÉTICA}

\section{Sistema vocálico}

a) Vocales iniciales

No sufren apenas modificaciones. Hay algunos casos de aféresis, pero son muy pocos, mientras en Sánchez de Badajoz y Lope de Rueda aparecen con frecuencia ${ }^{38}$, y no hay ninguna en las Coplas de Reinosa. En la Farsa de la castidad de Lucrecia el negro dice qui por aquí; en la Comedia Tesorina, qui (aquí), forcar (ahorcar), güelo (abuelo); es la única que modifica una vocal inicial: uberta por abierta. En la Segunda Celestina, namorado por enamorado, aféresis que es frecuente entre personajes que no son negros, como los rústicos.

\section{b) Vocales mediales}

El empleo de las vocales mediales se aleja bastante de la norma lingüística, con numerosos casos de alteración del timbre, aunque las preferencias varían de uno a otro texto. Así, en las Coplas de Reinosa se lee carrajador por corregidor; en la Farsa de la castidad de Lucrecia y la Comedia Teso-

87 Juan Ruiz, Libro de Buen Amor, ed. J. Joset, Madrid, Espasa-Calpe, 1974, vol. II, pág. 236. Aparece el término también en Miguel de Cervantes, Los baños de Argel, ed. J. Canavaggio, Madrid, Taurus, 1984, v. 301, pág. 69; glosario, pág. 160.

s8 F. Weber de Kurlat, "El tipo cómico ...", pág. 166. 
rina se opta por la transformación de $e$ medial en $i$, en bastantes ocasiones (digir por decir, dixar por dejar, riñigase por renegase en la Tesorina; xiñor por señor en la Farsa de Lucrecia). En la Tesorina hay dos casos de $u$ por $o$ : bufitón por bofetón y dun por don. En cambio, en la Segunda Celestina hay un solo caso de transformación de $a$ en o (Mohoma) y abunda la sustitución del sonido $i$ por el $e$, lo que no obsta para que también haya ejemplos contrarios: alternan dezir, dezer y dizir.

Estas vacilaciones, tanto en el sistema vocálico como en el consonántico, son una característica sistemática del habla de negros en estos primeros textos. A pesar de ello, no cabe deducir que esto se deba a la "inconsistencia de su comportamiento verbal que hace inútil el estudio de su forma de hablar" ${ }^{39}$, sino que coincide con lo que sabemos del sistema vocálico de las lenguas africanas, que "registra una amplia gama de matices en las series anterior y posterior, con tendencia frecuente además al uso de vocales mixtas y nasales, de timbre oscuro e impreciso ..." $₫$.

En cuanto a los diptongos, sin casi excepciones, se opta por deshacerlos. Para F. Weber, éste es un rasgo constante del negro desde Rodrigo de Reinosa y piensa que se trata de una influencia general del portugués, opinión compartida por E. de Chasca. Aunque es posible, resulta curioso que también sea frecuente la supresión de los diptongos en el habla de los moriscos ${ }^{41}$.

En cualquier caso, también en el caso de los diptongos hay excepciones a la norma y alternan en un mismo texto términos en los que se conservan con otros en los que se suprimen.

\section{c) Vocales finales}

La modificación de las vocales finales suele ser manifestación de deformaciones morfológicas, por lo que se estudiarán en otro apartado. En las

\footnotetext{
30 Afirmación de Cotarelo recogida por E. de Chasca en el art. cit., pág. 323.

40 Alvarez Nazario, op. cit., págs. 117-118.

41 Menéndez Pidal señalaba en su ed. del Poema de Yuçuf (pág. 37) que "no aparece en la escritura aljamiada la confusión $e$ por $i$ que traen algunos de los que remedan el habla morisca. Lope de Rueda (Armelina) "amega", "dexer" (por decir), "picador" (por pecador). En algún caso también deshace el diptongo, como en "voxtra". En la Farsa de los lenguajes, Colección de Autos, Farsas y Coloquios del Siglo XVI. Ed. Léo Rouanet, New York, Georg Olms Verlag Hisdesheim, tomo III, págs. 329-345, 1979 (Bibliotheca Hispánica, Barcelona, Madrid, 1901), encontramos asimismo casos de alteración del timbre de la $e$ por el de la $i$, y de desaparición de los diptongos ue $>0$ y ie > e " "bon" (buen), "xonior" (señor), "qui" (que), "di" (de), "istar" (estar), "xempre" (siempre), "ben" (bien), "creado" (criado), "dux" (dios), "servendo" (sirviendo), "noxo" (nuestro) ... Quizás con el guineo suceda lo mismo, que las alteraciones vocálicas no correspondan exactamente a la realidad lingüística de los negros esclavos.
} 
Coplas de Reinosa, caravaju y lagartu son los únicos ejemplos de alteración de timbre; en la Segunda Celestina, en cambio, se opta por sustituir la vocal final por la $e$ : carte (carta), Crexte (Cristo), mientras algunas veces se añade otro sonido, siempre en palabras paroxítonas: Xantar (Santa), Pandulfox (Pandulfo), Palanax (Palana).

En resumen, respecto a los sonidos vocálicos, los cambios más frecuentes del "guineo" son la reducción de los diptongos y la alteración, bastante arbitraria, del timbre. Estas modificaciones son frecuentes también en el habla de otros personajes cómicos, como los de los moros. No parece, a falta de un estudio riguroso sobre estas jergas en el teatro, que el sistema vocálico ofrezca una estructura propia y sistemática que permita diferenciar claramente unas de otras. Aunque esta vacilación podría responder a una realidad lingüística, no es posible afirmar que tal o cual preferencia, distinta según los autores, se deba más que a razones subjetivas.

\section{Sistema consonántico}

a) Consonantes iniciales

En algunas ocasiones la modificación de la consonante inicial se debe al influjo del portugués. Sucede esto con falar, farto, fambrento, en las Coplas de Reinosa ; asimismo, la conservación de la $f$ inicial en fugir y fuxir, en la Segunda Celestina, parece deberse a la contaminación del portugués fogir, término que emplea el negro de la Farsa de Lucrecia. En la Comedia Tesorina, la negra Margarita dice forcar por 'ahorcar', aunque en otras ocasiones conserva la $h$ inicial (horca, hablar, etc.). En general, se emplea la $f$ inicial en casos aislados, mientras que Lope de Rueda la prodigará mucho más.

La sustitución del fonema palatal lateral sonoro |1 por el prepalatal africado sordo $|\hat{\mathbf{c}}|$ en chamar y chegar, en la Segunda Celestina, coincide también con términos portugueses, aunque, como es habitual, no tengan dificultades en decir correctamente llegar. Este trueque no se produce en los demás textos; en cambio, en ellos hay algún ejemplo de yeísmo, sin llegar a ser generalizado: en la Tesorina, yorar, y en la Tercera Celestina, yamar y yegastes.

La alteración más frecuente y sistemática de las consonantes iniciales es la que afecta al fonema ápico-alveolar cóncavo $|s|$, que se sustituye, casi siempre, por el prepalatal fricativo sordo |š|. En la Segunda Celestina predomina esta modificación, xaber, xabendo, xi, xeñora, etc., y son menos las ocasiones en las que se conserva la $s$ inicial. Sucede lo mismo en la Comedia Tesorina (xartar, xaber, xemana, xuegra, etc.), en la Tercera Celestina (xaber, xeñora, 
$x i$, xervir, etc.) y en las dos frases de la esclava negra de La lozana andaluza (xeñora, xi). En la Farsa de Lucrecia, en cambio, es más frecuente que se mantenga la $s$ inicial (ser, servidor, salir, etc.), sólo se modifica en el caso de $x$ iñor, que se repite en varias ocasiones. La distinción entre la $b$ bilabial oclusiva y la $v$ fricativa es casi total en todas estas obras. Hay algún caso de betacismo en la Tesorina (box, boxtro), pero también vox, voxtro; sin embargo, los betacismos, según F. Weber, son frecuentes en la obra de Lope de Rueda, y sistemáticos en las de Diego Sánchez de Badajoz ${ }^{42}$.

Por último, la Tesorina es la única entre estas obras en la que se dan casos de sustitución de $l$ inicial por $r$ : rágrimas (lágrimas), ra (la), ro (lo). En este rasgo se acerca a Sánchez de Badajoz, en cuyas Farsas se produce una enorme abundancia de sonidos vibrantes, en posición inicial y medial, como rasgo caracterizador del habla de negros.

b) Consonantes mediales

1. Alteraciones del timbre

\section{1. $|\mathbf{s}|$ por $|\mathbf{s}|$}

Es la modificación más frecuente, como sucedía con las consonantes iniciales, aunque excepcionalmente se conserve también el fonema ápico-alveolar. En la Segunda Celestina encontramos caxa, coxillas, dexta, extar, voxa, etc., y, excepcionalmente, estar, hasta, despox, etc. Sucede lo mismo en la Tercera Celestina, en la que Boruga dice: acaxa (acaso), anxi, etc., y también estar. La Comedia Tesorina es la más sistemática, pues se hace este trueque en todos los casos de $s$ medial; por el contrario, la Farsa de Lucrecia conserva la única $s$ medial que aparece: hasta ${ }^{48}$.

En las Coplas de Reinosa hay solamente dos casos de este "xexeo", que es la característica común del grupo de textos objeto de este trabajo. Ahora bien, se trata de sibilantes en posición agrupada sk: moxca y moxquito. El trueque de sibilantes es muy frecuente en esta posición (coxquear en La Celestina o en el Lazarillo) y está ampliamente documentado en el caso concreto del término moxca ${ }^{\star}$. Por esta razón, pienso que no se trata de ejem-

42 F. Weber de Kurlat, El tipo cómico ..., pág. 146.

48 El morisco de la Farsa de los lenguajes, que utiliza el sonido "sh" en vez de las " $s$ " iniciales, mantiene la $s$ en posición interior de palabra, con la excepción de "noxo" por "nuestro".

* Véase A. Alonso, art. cit., pág. 3. En el Coloquio de la moxca y la hormiga se escribe siempre con $x$. Para esta edición: Ana Vian, "Fábula y diálogo en el Renacimiento: confluencia de géneros en el Coloquio de la moxca y la hormiga de Juan de Jarava", Arcadia, Homenaje a D. Francisco López Estrada (en prensa). 
plos de "xexeo" en el habla de negros, sino de un trueque que en determinadas áreas del castellano no producía asombro, ni siquiera en el siglo XvII, a juzgar por las afirmaciones de Correas o Aldrete ${ }^{45}$; aunque, como es sabido, molestase profundamente a Juan de Valdés, muchos años antes.

\section{2. $|\check{\mathbf{s}}|$ por $|\hat{\mathbf{z}}|$}

Esta modificación es menos frecuente y general. En la Segunda Celestina coinciden las formas dezir, dizir, dexer y dexir (todas por 'decir'), incluso dentro del mismo parlamento; también aparecen hazer, hazenda junto a haxer, parescer, parecer y parexer. En la Tercera Celestina se encuentran ejemplos parecidos: hazenda y dexir.

En la Comedia Tesorina nos encontramos con que, en casos similares, la grafía es $j$, que normalmente representa el sonido de la prepalatal fricativa sonora: hajer, ajer (hacer), anjuelo (anzuelo). La presencia de los términos mintiroja (mentirosa), caja (casa) y tinojo (tiñoso) coincide con ejemplos documentados en los siglos XV y xvI, en los que se evidencia la alternancia de sonoras, como parasismo-parajismo, visitar-vigitar, residente-regidente, etcétera ${ }^{\star 6}$. Pero si tenemos en cuenta que en todos los demás casos este texto transforma la $s$ medial en $x$, podría tratarse de una muestra del ensordecimiento del sonido $|\hat{z}|$ (representado por las grafías $g, j$ ); precisamente es en Aragón (lugar en el que vivía Huete, y donde escribió la Comedia Tesorina) donde "parece haberse adelantado este ensordecimiento de las sibilantes sonoras, pues los mss. intercambian $x$ - $j$-ch desde el siglo xiv" ${ }^{47}$. En ese caso, las formas de hajer, anjuelo, etc., reflejarían un trueque similar a los de la Segunda Celestina y Tercera Celestina.

\section{3. $|\mathrm{r}|$ por $|1| \mathrm{y}|\mathrm{r}|$ por $|\mathrm{d}|$.}

La sustitución de la $l$ por la $r$, en posición agrupada, es habitual en la jerga de pastores rústicos y vulgarismo tópico en multitud de textos, entre distintos tipos de personajes, siempre de baja extracción social. Tanto $\mathrm{E}$. de Chasca como F. Weber citan abundantes ejemplos en los que se intercambian estos sonidos en el habla de negros. Sin embargo, sólo en la Tercera Celestina y en la Comedia Tesorina, de entre este grupo de obras, se dan casos de

\footnotetext{
4 A. Alonso, art. cit., pág. 4.

4 Ibíd., pág. 7.

4 Ibid., pág. 11, n. 17.
} 
esta clase de trueques. En la Tercera Celestina, Boruga dice Porandra (Polandria), habrar (hablar), parabras (palabras), prazer (plazer), toro (todo), porer (poder), cuyrar (cuydar), poriro (podido), daro (dado) y xirebaro (se llevaron), pero también ablax (hablas).

\section{Supresión de grupos consonánticos}

F. Weber señala que las dificultades que plantearían estos grupos podrían ser superadas por dos procedimientos: "o desarrollando un sonido vocálico entre las consonantes en contacto, como ocurre en Gil Vicente (...), o suprimiendo una de las dos consonantes" ${ }^{48}$.

Sin embargo, no dan muestra de tener problemas para la pronunciación de grupos consonánticos ninguno de los negros de este grupo de obras. En la Segunda Celestina, moxarte por 'mostrarte' es el único ejemplo; pero en varias ocasiones se emplea, en boca de otros personajes, la variante muessa por 'muestra', que es ejemplo paralelo al de vuessa por 'vuestra'. Los negros también dicen voxa por 'vuessa' con supresión del diptongo y transformación de $s$ en $x$. En la Farsa de Lucrecia, el negro de Tarquino dice en una ocasión apata, en vez de 'apartar', pero pronuncia correctamente negro y servidor ${ }^{\star \theta}$.

\section{c) Consonantes finales \\ 1. Alteración del timbre}

Se suele cambiar el sonido $|\mathbf{s}|$ final por el $|\check{s}|$, tanto en las formas del singular como en las del plural, aunque, como casi siempre, también hay excepciones y conviven en el mismo texto términos terminados en $s$ y en $x$.

En la Segunda Celestina predominan las terminaciones en $-x$ : burlax, $d a x$, lox, dux (dios), max, despox, etc., pero también las, los, mas, pues, etc. En esta obra, la $-l$ final se convierte en $x$ tras la contracción en conex, que se emplea para el masculino singular 'con él' y para el femenino plural 'con ellas'. No aparece esta modificación en ningún otro texto.

La Comedia Tesorina es la más sistemática, modifica el timbre en todos los casos de $-s$ final salvo vos en una ocasión. La Farsa de Lucrecia no lo

48 F. Weber de Kurlat, "El tipo cómico ...”, págs. 163-164.

- La esclava de La Lozana andaluza responde, cuando Lozana le pregunta su nombre: "llamar Penda de xeñora", lo que pudiera referirse a que es la "prenda" de su señora; habría entonces una eliminación del grupo pr. 
modifica y la Tercera Celestina muestra casi el mismo número de palabras con una y otra terminación, con cierto predominio de la conservación de la $-s$ final ${ }^{\text {so. }}$.

\section{Supresión y adición de consonante final}

La supresión y la adición de consonantes al final de las palabras, en la mayor parte de los casos, evidencia los problemas que planteaba la concordancia para estos personajes. Así, en la Tesorina encontramos malox (mala), malax (mal), y también xirebaro (se llevaron) y acorde (acuerdes). En la Segunda Celestina, callax (calla), jurax (juro), todox (todo), e incluso en algunos nombres propios: Palanax (Palana), Pandulfox (Pandulfo) y Paltranax (Paltrana). Excepcionalmente, se añade una $-r$ en Xantar (Santa). Sólo suprimen la $d$ final en merxé (merced) y vertú (virtud); no parece que se trate de una característica del habla de negros, por cuanto se trata de vulgarismos habituales entre personajes de baja extracción social.

\section{Primeras Conclusiones}

No es mi intención solucionar el problema de en qué medida el "guineo" refleja el habla real de los esclavos africanos que vivían en España a principios del siglo xvi. Para ello es necesario un conocimiento de la historia de lenguas africanas y del "pidgin" que se hablaba en los tratos comerciales de las factorías esclavistas. Además, los textos literarios no son documentos que pretendan reproducir la realidad lingüística, mucho menos en el caso de minorías marginales; por ello deben ser manejados con precaución, máxime en una etapa histórica de profundo reajuste fonético del castellano, como es la del siglo xvi.

El propósito de esta parte del trabajo es comprobar si los cinco textos de la primera mitad del siglo xvi en los que el "xexeo" es una de las características del habla de negros comparten más rasgos fonéticos $\mathrm{y}$, al mismo tiempo, difieren en otros respecto a aquellos textos en los que los negros no "xexean". Si esto es así, se podría afirmar que la jerga de estos personajes, en una primera etapa literaria, se presenta de dos formas claramente tiferenciadas desde el punto de vista fonético, y tras Lope de Rueda una de ellas desaparecerá.

oo El morisco de la Farsa de los lenguajes dice: "dax", "Dux" (Dios) y "días". "Dux" por "Dios", además de en la obra anterior, aparece en la Segunda Celestina y en Diego Sánchez de Badajoz. 
Respecto al sistema vocálico, no hay diferencias claras entre este grupo de textos y los de Diego Sánchez de Badajoz, Lope de Rueda o Gil Vicente. Las modificaciones son, aparentemente, muy arbitrarias en ambos grupos de obras; coinciden también con la jerga morisca en algunos aspectos.

En el sistema consonántico, en cambio, se advierten peculiaridades fonéticas que no coinciden con las que se han venido señalando como específicas del habla de negros.

E. de Chasca y Alvarez Nazario señalan que son frecuentes los trueques de $d$ por $r, d$ por $l, l$ por $r$ y $r$ por $l$, la tendencia a la nasalidad y la supresión de consonantes no nasales como sonidos finales, especialmente en el caso de la $-s$. A estas características añade F. Weber la importancia de los betacismos en ciertos textos, la conservación de $f$ inicial, el yeísmo, la adición de $-s$ a términos en singular (sobre todo en las Farsas de Sánchez de Badajoz) y la simplificación de grupos consonánticos.

Sorprendentemente, en las Coplas de Rodrigo de Reinosa, primera aparición literaria de personajes negros, no se encuentra casi ninguna de estas características fonéticas; la presencia de $f$ inicial es la única excepción, pero hay que tener en cuenta que, en buena medida, se debe a la abundancia de portuguesismos.

Tampoco en la Segunda Celestina se producen estas deformaciones fonéticas. En la Comedia Tesorina, la negra Margarita pronuncia en ocasiones $r$ por $l$ o por $d$ (picarora, rágrimax, re, poriro, etc.), hay algún caso de betacismo (box, boxtro) y de yeísmo (yorar, yorando).

En la Tercera Celestina también se convierten la $l$ y la $d$ en $r$, en algunos términos (vira, toro, habra, etc.), hay dos casos de yeísmo (beyaca, cayar) y dos de betacismo (beyaca, bex).

En resumen, las características del habla de negros en los textos en que “xexean" frente a los de D. Sánchez de Badajoz, Lope de Rueda y GilVicente son las siguientes:

- Transformación generalizada de la $s$ en $x$ en cualquier posición; la Farsa de la castidad de Lucrecia es la que menos se aleja de la norma lingüística.

- Conservación de los grupos consonánticos.

- Ausencia o escasez de betacismos.

- Ausencia total de nasalización.

- Conservación de vibrantes simples y múltiples.

- Escasa conservación de la $f$ inicial.

- Yeísmo y trueque de $r$ por $l$ y por $d$ solamente en algunos términos de la Comedia Tesorina y de la Tercera Celestina. 


\section{MORFosintaXis}

El habla de los negros literarios se aleja de la norma también por una serie de rasgos morfosintácticos que, en gran parte, son comunes desde los primeros textos del Cancioneiro Geral de Resende.

P. Teyssier dice a propósito de estas composiciones: "La langue de cette négrèsse est, comme on voit, tout à fait comparable à celle du nègre de Fernao da Silveira: syntaxe et morphologie rudimentaires, verbes à l'infinitif, a mim par eu, estar par ser ..." s1.

En un trabajo posterior, A. Naro expone las características del sistema gramatical propio de la lengua de reconocimiento entre africanos y portugueses, relacionándola con ejemplos del habla de negros en la literatura portuguesa, tomados de Gil Vicente y Chiado. Estas características son ${ }^{52}$ :

- En el sistema verbal, formas invariables para cada verbo: las inflexiones verbales se indican con partículas o adverbios.

- Uso de pronombres tónicos para todas las funciones sintácticas.

- Negación mediante la forma tónica y enfática nunca, en vez de no.

- Escasez de preposiciones, que son sustituidas por una o dos formas exclusivamente.

- Pérdida de concordancia de género y número en el sistema nominal.

- Uso infrecuente de la subordinación.

- Preferencia por la yuxtaposición, en vez de la coordinación.

- Pérdida de artículos y otros determinantes nominales.

Páginas después, resume las notas propias del habla de los moros, con el apoyo del trabajo de Sloman:

(a) $s z>\check{s} \check{z}$; (b) infinitives in place of finite verb forms; (c) $m i$ in place of the 1sg. subject pronoun, and (d) confusion of ser and estar. However, (...) there are no unbound stressed adverbial particles for tense aspect, despite the consistent use of the infinitive; negatives are given with no, rather than nunca; nouns have lexical gender, (...) articles and other unstressed nominal determiners are present, etc. (...). Note in this connection that the so-called negros of Silva's Segunda comedia de Celestina were probably intended to be North Africans, since they use precisely the four characteristics given above and almost no other ${ }^{88}$.

-1 P. Teyssier, op. cit., pág. 230.

62 A. Naro, art. cit., págs. 328-333.

$₫$ Ibid., pág. 338. 
Pienso que esta afirmación es un poco precipitada, pues, sin ir más lejos, sucede lo mismo en las Coplas de Rodrigo de Reinosa; en ellas los negros usan el adverbio no en varias ocasiones, emplean distintos determinantes $y$ son contados los errores de concordancia (lo corpo). Por otro lado, la coordinación copulativa es muy abundante y hay varios casos de subordinación. Pese a ello y a la presencia de arabismos (taibo, marfuz y gualá), no hay duda de que Reinosa trata de remedar el habla de negros. Además, nos encontramos incorrecciones como las que ya señalaba Teyssier : a mi llamar ... en vez de 'yo me llamo ...', pero también emplean la forma de pronombre personal en función de sujeto, yo; prefieren el uso del infinitivo al de las flexiones verbales, aunque utilizan bastantes formas verbales correctamente. Otro tanto sucede con la confusión de los verbos ser y estar: "Estar yo buen negro de obispo criado / y ser de Gelofe ..."

La negra de La lozana andaluza usa el infinitivo por el presente de indicativo.

También el negro de Tarquino de la Farsa de Lucrecia simplifica de este modo la flexión verbal y confunde ser y estar. La irregularidad en su forma de construir las oraciones compuestas se pone de manifiesto en los siguientes versos: "yo quedar guardar qui, / hasta que xiñor salir, / y negro nunca fogir / aunque más salir a mi ; / ...”. En el primer verso se prefiere la yuxtaposición, pero en los demás no parece tener problemas para el uso de un variado tipo de nexos. Sin embargo, este negro se distingue de los demás porque no vacila con la forma yo. Sólo comete un error de concordancia: “ $i a$, xiñor! isa be venida!”.

Margarita, la negra de la Comedia Tesorina, es el personaje que más se aleja de la norma lingüística, de entre los que "xexean". Su forma de conjugar los verbos es muy caprichosa; mientras algunas veces sustituye formas flexionadas por el infinitivo ("Qui xtar y"), otras las emplea incorrectamente (ya vene, por 'ya vengo'; me coxto por 'me cuesta') y algunas lo hace correctamente (extar mi sempre dormendo). En cuanto a los pronombres, sustituye el personal de primera persona en función de sujeto por el tónico $m i$, en vez de sustituirlo por $a$ mí, la forma más frecuente en los demás textos. Son asimismo abundantes las confusiones y las duplicaciones innecesarias ('no las agas murir, mi por 'no me hagas morir', yo mi la quieria forcar por 'yo me quería ahorcar'). A diferencia de los demás, no es tan sistemática la confusión entre ser y estar; pero, sobre todo, se caracteriza porque la falta de concordancia en el sistema nominal es casi habitual, mientras en los otros casos se da de forma esporádica (malox vintura, un horca, er braça, malax año).

Así y todo, su forma de hablar tampoco coincide con algunas de las características que A. Naro señala; no emplea el adverbio nunca en vez de la 
negación no, construye algunas oraciones subordinadas que tienen cierta complicación, y mantiene el uso de los determinantes y de las preposiciones, aunque no siempre.

En la Segunda Celestina, Boruca y Zambrán emplean el infinitivo en vez de otras formas verbales; por el presente de indicativo (querer por 'quieres'), por el imperativo (andar con $D u x$ en vez de 'anda con Diox'), por el pretérito imperfecto (extar por 'estaba') y por el futuro (a mi caxar contigo en vez de 'yo me casaré contigo'). En comparación, son muy pocas las formas verbales correctas: venex, deben andar, foxte, xabendo, etc. En algún caso se utiliza una flexión verbal incorrecta: jurax por 'juro', callax por 'calla'.

Es asimismo habitual la confusión entre ser y estar, y, en general, prefieren el verbo estar para los dos significados: “... xi tú quier extar hombre de ben, a mí querer xer leal a mi xeñora”, “... y no estar bona cortexia ..."; "a mí no estar tan bovo como tú penxar ...”; “... qu' extar veliaco ..."; "... extar todo boverías ..."; etc.

El sistema pronominal parece ser especialmente complicado para estos negros. Sustituyen el pronombre sujeto de primera persona yo por a mí siempre, con sólo tres excepciones, y usan adecuadamente las demás formas pronominales de sujeto.

El empleo de las formas átonas es muy vacilante: en algunos casos - los menos- es correcto (encomendarme a Zambrán por 'encomiéndame a Zambrán'). En otros se suprime el pronombre (chegar acá por 'llégate acá', dexer por 'dile', que dexar por 'que se deje'...) y en los más se sustituye por alguna forma tónica (que no querer a él mucho por 'que no le quieres mucho').

Se respeta, casi siempre, la concordancia de género y número, con sólo dos excepciones (conex 'con ella', un carte 'una carta'), a diferencia de lo que sucedía en la Comedia Tesorina, pero es lo habitual en los demás textos, incluidas las Coplas de Reinosa.

También respetan el uso de las preposiciones. Construyen asimismo oraciones compuestas de todo tipo, sin manifestar dudas con los distintos nexos, que se suprimen en contadas ocasiones (Que a mi xaber salir ayer de..., 'que yo sé que salió ayer de ...').

En la Tercera Celestina, en general no se siguen las pautas de la Segunda en los rasgos fonéticos, como ya hemos señalado, pero sí gran parte de los morfosintácticos que hemos visto hasta ahora en las demás obras. Sin embargo, y teniendo en cuenta que su autor también reproduce el habla de un vizcaíno, da la impresión de que Boruga mezcla rasgos de ambas formas de hablar, porque la construcción sintáctica de algunas de sus oraciones recuerda el estilo entrecortado que se suele poner en boca de los vizcaínos, con el 
verbo al final de la frase. ("Para yo dexemulaxones no estar a mí taibo, que si oxo mira el derecho a punta, a mí entendendo que veryel yegastes, y honrras dexas, que muger e gaína por andar perden ayna" ... "Si habra no vuiesse, obra no extaría, que do falta palabras no xobra hecho”.)

En resumen, las alteraciones morfosintácticas del habla de negros en estos textos serían las siguientes:

- Predominio del infinitivo sobre otras formas de flexión verbal.

- Confusión de ser y estar y empleo más generalizado de estar para ambos usos.

- Empleo de a mi o mí por yo y, en general, preferencia por las formas pronominales tónicas en vez de las átonas.

- En la Comedia Tesorina es casi sistemática la falta de concordancia en el sistema nominal, mientras en las demás obras estudiadas sólo se da en casos aislados.

\section{ConCLusión}

En todos estos textos se pueden observar coincidencias fonéticas y morfosintácticas en el habla de negros. Ciertamente, no se puede hablar de identidad total; cada uno de los autores reproduce con alguna particularidad propia esta jerga. Sin embargo, es relevante el hecho de que no incluyan muchas de las modificaciones que se encuentran en otras obras coetáneas o próximas, como las de Sánchez de Badajoz y Lope de Rueda.

En cierto modo, la Comedia Tesorina y la Tercera Celestina están a medio camino entre dos formas de representar el habla de negros en la primera mitad del siglo XVI; dos convenciones que en un primer momento conviven y de las que desaparecerá una - la del "xexeo"- en aras de la mayor eficacia dramática.

Las razones literarias por las que se consolida el habla de los negros que no "xexean" son claras. Si se pretende ampliar el catálogo de personajes cómicos con los moriscos, que también convertían la $s$ en $x$, como hace Lope de Rueda en la Armelina, era necesario independizar los rasgos lingüísticos de ambas etnias. No son tan claras las razones lingüísticas por las que en su primera andadura literaria hay pautas distintas para representar el guineo; es un problema que sólo podrán resolver los estudios sobre la lengua de reconocimiento y su adaptación al castellano. 